\title{
Commentary: Effects of Age and Initial Risk Perception on Balloon Analog Risk Task: The Mediating Role of Processing Speed and Need for Cognitive Closure
}

\author{
Lukasz Walasek* \\ Psychology, University of Warwick, Coventry, UK
}

Keywords: aging, risk-taking, balloon analog risk task (BART), cognitive modeling, dual-system theories

\author{
A commentary on
}

Effects of Age and Initial Risk Perception on Balloon Analog Risk Task: The Mediating Role of Processing Speed and Need for Cognitive Closure

by Koscielniak, M., Rydzewska, K., and Sedek, G. (2016). Front. Psychol. 7:659. doi: 10.3389/fpsyg.2016.00659

\section{OPEN ACCESS}

Edited by:

Emma V. Ward,

Middlesex University, UK

Reviewed by:

Johannes Schiebener,

University of Duisburg-Essen,

Germany

*Correspondence:

Lukasz Walasek

I.walasek@warwick.ac.uk

Specialty section:

This article was submitted to

Cognition,

a section of the journal

Frontiers in Psychology

Received: 11 July 2016 Accepted: 18 August 2016 Published: 29 August 2016

Citation:

Walasek L (2016) Commentary: Effects of Age and Initial Risk Perception on Balloon Analog Risk

Task: The Mediating Role of

Processing Speed and Need for

Cognitive Closure.

Front. Psychol. 7:1320.

doi: 10.3389/fpsyg.2016.01320
Existing research strongly suggests that age-related changes in the cognitive system influence preferential choice. While the reduction of fluid cognitive ability can lead to sub-optimal decision outcomes (Finucane et al., 2000), experience garnered during one's lifespan can also improve one's decision making (Mata et al., 2007; Bruine de Bruin et al., 2014). How can research on aging and decision making explain such mixed results? A reasonable approach is to adhere to a clear definition of optimality in choice behavior, which must be grounded in principles of cognitive psychology. Indeed, this approach has led many researchers to identify distinct cognitive processes that may be responsible for suboptimal decisions among older adults. Among many, these include memory (Buckner, 2004), perception (Schneider and Pichora-Fuller, 2000), and executive functions (Schiebener and Brand, 2015).

In this special issue, Koscielniak et al. (2016) focus on the effect of aging on risky choice. Comparing the performance of two age groups, they found that older female adults exhibit a lower propensity to take risks on the Balloon Analog Risk Task (BART). At the same time, their results showed that both younger and older females adapt to initial failures and successes and are capable of adjusting their risk taking behavior over the course of repeated trials. Koscielniak et al. (2016) positioned their findings within the broader framework of the dual-system reasoning, attributing the overall poor performance of older adults to a "decline in deliberative processes" (p. 6).

In this commentary, I offer a cautionary note about the reliance on such theoretical frameworks to make predictions about the cognitive underpinnings of preferential choice. While the conclusions drawn by the authors are supported by their data, the use of verbal (i.e., not quantitative, Lewandowsky and Farrell, 2011) theories can lead to erroneous inferences. Instead, future advances should rely on cognitive modeling to decouple competing mechanisms that can give rise to differences in choices between younger and older adults. In challenging verbal and descriptive (i.e., statistical) models in study of risky choice and aging, many now argue that cognitive modeling removes ambiguity associated with the interpretation of cognitive processes (Lewandowsky and Farrell, 2011). In the case of the BART itself, several models have been proposed, each specifying specific cognitive mechanisms behind decisions to either pump or to 
secure one's earnings (Wallsten et al., 2005; Schmitz et al., 2016). In a 4-parameter version of the model by Wallsten et al. (2005), for example, $\alpha$ and $\mu$ parameters control the learning rate at which one's belief that a balloon will burst on a given trial is updated, $\gamma^{+}$represents the general propensity to take risks, and $\beta$ captures the behavioral consistency of the agents. Crucially, Wallsten and colleagues showed that parameters recovered in their study correlated with self-reported indices of risky behaviors, supporting the view that their specification of the model captures the cognitive components of risk taking in BART (but see a discussion of alternative models by van Ravenzwaaij et al., 2011). In fact, research has found that the differences between young and old on BART performance can be attributed to heightened reward-sensitivity and the initial perception of risk (Cavanagh et al., 2012), as opposed to differences in the ability to update beliefs based on observed outcomes (Rolison et al., 2012). These results are consistent with the efforts of Koscielniak et al. (2016), but the results of model fitting present a clear advantage over verbal theories for a number of reasons.

First, interpretable parameters of the model applied to BART can be used to draw parallels with other areas in which the effect of aging has been studied. Comparisons with performance on other risk tasks (and of other populations) can produce converging evidence about the cognitive processes involved. This is particularly important as it reduces the chance that a particular paradigm (e.g., BART) becomes the subject of empirical research in itself. Second, cognitive modeling can lead to alternative interpretations concerning risky choice. To illustrate this point, consider a widely held belief about the negative correlation between cognitive ability and risk aversion (e.g., Dohmen et al., 2010). Recent findings by Andersson et al. (2013) showed that this association is in fact spurious and simply reflects an increased rate of random choice among those with lower cognitive ability. Although the authors did not use cognitive modeling to illustrate their finding, it is easy to see that in many cases such mistakes

\section{REFERENCES}

Andersson, O., Tyran, J.-R., Wengström, E., and Holm, H. J. (2013). Risk Aversion Relates to Cognitive Ability: Fact or Fiction? (IFN Working Paper No. 964). Department of Economics, Lund University.

Bruine de Bruin, W., Strough, J., and Parker, A. M. (2014). Getting older isn't all that bad: better decisions and coping when facing "sunk costs". Psychol. Aging 29, 642-647. doi: 10.1037/a0036308

Buckner, R. L. (2004). Memory and executive function in aging and AD: multiple factors that cause decline and reserve factors that compensate. Neuron 44, 195-208. doi: 10.1016/j.neuron.2004.09.006

Cavanagh, J. F., Neville, D., Cohen, M. X., Van de Vijver, I., Harsay, H., Watson, P., et al. (2012). Individual differences in risky decision-making among seniors reflect increased reward sensitivity. Front. Neurosci. 6:111. doi: 10.3389/fnins.2012.00111

Dohmen, T., Falk, A., Huffman, D., and Sunde, U. (2010). Are risk aversion and impatience related to cognitive ability? Am. Econ. Rev. 100, 1238-1260. doi: 10.1257/aer.100.3.1238

Finucane, M. L., Mertz, C. K., Slovic, P., and Schmidt, E. S. (2005). Task complexity and older adults' decision-making competence. Psychol. Aging 20, 71-84. doi: 10.1037/0882-7974.20.1.71 could be avoided if a correctly specified model with a noise parameter was fit to the data. In the context of BART and aging, existing models can discern between noisiness of responding and risk preferences, and they are therefore well equipped to recover such patterns. Indeed, previous studies have found that older adults are less consistent in their decisions (Finucane et al., 2005). Finally, cognitive models can be extended to study dynamic aspects of cognition. Much work has applied drift diffusion models to understand cognitive performance of younger and older adults on a range of tasks (Ratcliff et al., 2006; McKoon and Ratcliff, 2013). Such models take into account response times and can therefore tell us more about the timeaccuracy tradeoffs involved in a decision process. This modeling approach is particularly suitable for studying the effects of aging, as older participants often adapt their strategies to account for the decline in their fluid cognitive ability (Smith and Brewer, 1995).

In sum, Koscielniak et al. (2016) contribute to the understanding of how cognitive and motivational factors influence preferential choice at different ages. This commentary highlights the fact that future research can build on these findings using cognitive modeling techniques to identify specific aspects of the cognitive process that impact risk preferences among young and old adults. Such efforts correspond to a shift from verbal and descriptive models toward quantitative models of cognition.

\section{AUTHOR CONTRIBUTIONS}

The author confirms being the sole contributor of this work and approved it for publication.

\section{FUNDING}

This work was supported by Leverhulme Trust Grant RP2012-V-022.
Finucane, P. A., MacGregor, M. L., and Slovic, P. (2000). “The bearable lightness of aging: judgment and decision processes in older adults," in The Aging Mind: Opportunities in Cognitive Research, eds P. C. Stern and L. L. Carstensen (Washington, DC: National Academies Press), 144-165.

Koscielniak, M., Rydzewska, K., and Sedek, G. (2016). Effects of age and initial risk perception on balloon analog risk task: the mediating role of processing speed and need for cognitive closure. Front. Psychol. 7:659. doi: 10.3389/fpsyg.2016.00659

Lewandowsky, S., and Farrell, S. (2011). Computational Modeling in Cognition: Principles and Practice. Thousand Oaks, CA: SAGE.

Mata, R., Schooler, L. J., and Rieskamp, J. (2007). The aging decision maker: cognitive aging and the adaptive selection of decision strategies. Psychol. Aging 22, 796-810. doi: 10.1037/0882-7974.22.4.796

McKoon, G., and Ratcliff, R. (2013). Aging and predicting inferences: a diffusion model analysis. J. Mem. Lang. 68, 240-254. doi: 10.1016/j.jml.2012.11.002

Ratcliff, R., Thapar, A., and McKoon, G. (2006). Aging, practice, and perceptual tasks: a diffusion model analysis. Psychol. Aging 21,353-371. doi: 10.1037/08827974.21.2.353

Rolison, J. J., Hanoch, Y., and Wood, S. (2012). Risky decision making in younger and older adults: the role of learning. Psychol. Aging 27, 129-140. doi: $10.1037 / \mathrm{a} 0024689$ 
Schiebener, J., and Brand, M. (2015). Decision making under objective risk conditions-a review of cognitive and emotional correlates, strategies, feedback processing, and external influences. Neuropsychol. Rev. 25, 171-198. doi: 10.1007/s11065-015-9285-x

Schmitz, F., Manske, K., Preckel, F., and Wilhelm, O. (2016). The multiple faces of risk-taking. Eur. J. Psychol. Assess. 32, 17-38. doi: 10.1027/1015-5759/a000335

Schneider, B. A., and Pichora-Fuller, M. K. (2000). "Implications of perceptual deterioration for cognitive aging research," in The Handbook of Aging and Cognition, 2nd Edn., ed T. A. Salthouse (Mahwah, NJ: Lawrence Erlbaum Associates Publishers), 155-219.

Smith, G. A., and Brewer, N. (1995). Slowness and age: speed-accuracy mechanisms. Psychol. Aging 10, 238-247.

van Ravenzwaaij, D., Dutilh, G., and Wagenmakers, E.-J. (2011). Cognitive model decomposition of the BART: assessment and application. J. Math. Psychol. 55, 94-105. doi: 10.1016/j.jmp.2010.08.010
Wallsten, T. S., Pleskac, T. J., and Lejuez, C. W. (2005). Modeling behavior in a clinically diagnostic sequential risk-taking task. Psychol. Rev. 112, 862-880. doi: 10.1037/0033-295X.112.4.862

Conflict of Interest Statement: The author declares that the research was conducted in the absence of any commercial or financial relationships that could be construed as a potential conflict of interest.

Copyright (c) 2016 Walasek. This is an open-access article distributed under the terms of the Creative Commons Attribution License (CC BY). The use, distribution or reproduction in other forums is permitted, provided the original author(s) or licensor are credited and that the original publication in this journal is cited, in accordance with accepted academic practice. No use, distribution or reproduction is permitted which does not comply with these terms. 